\title{
Review
}

\section{Molecular Testing for COVID-19: What the Clinician Should Know}

\author{
Nermin Kamal Saeed ${ }^{1,(\mathbb{D})}$, Mohammed Al-Biltagi ${ }^{2,3, *},(\mathbb{D})$, Adel Salah Bediwy ${ }^{2,3,(\mathbb{D})}$ \\ ${ }^{1}$ Pathology Department, Slamanyia Medical Complex, $\mathrm{MOH}$, Bahrain \\ ${ }^{2}$ Faculty of Medicine, Tanta University, Al Bahr Street, Tanta, Algharbia Province, Egypt \\ ${ }^{3}$ University Medical Centre, Dr. Sulaiman Alhabib Medical Group, King Abdulla Medical City, Arabian Gulf University, Bahrain
}

\author{
ARTICLE INFO \\ Article History \\ Received 24 November 2020 \\ Accepted 15 April 2021

\section{Keywords} \\ Coronavirus disease 2019 \\ molecular testing \\ reverse transcription polymerase \\ chain reaction \\ cycle threshold \\ viral shedding
}

\begin{abstract}
Coronavirus Disease 2019 (COVID-19) is a major challenge for health systems worldwide. Molecular diagnosis is a cornerstone in the management of COVID-19. Clinicians should understand the various aspects of molecular testing that may influence their judgment and management. Cycle threshold, viral shedding, and recurrence are among the most common areas of conflict among clinicians. In this review, we discuss these areas of conflict from a clinical perspective.
\end{abstract}

(C) 2021 Dr. Sulaiman Al Habib Medical Group. Publishing services by Atlantis Press International B.V. This is an open access article distributed under the CC BY-NC 4.0 license (http://creativecommons.org/licenses/by-nc/4.0/).

\section{INTRODUCTION}

The global pandemic of Coronavirus Disease 2019 (COVID-19) is a major challenge for national and international health organizations, not only because of its rapid transmission but also because of the conflict in diagnosis and treatment. Since the onset of the outbreak in December 2019 in Wuhan, China, there has been a continuous update in diagnostic tools. Despite the continuous update and improvement of diagnostic tools, we still face many diagnostic challenges. The diagnosis of COVID-19 depends on a history of exposure to an active case, clinical presentation, chest radiography computed tomography, and laboratory diagnosis. Laboratory diagnosis is used to confirm suspected cases of COVID-19, to screen asymptomatic individuals for intimate exposure to a definite patient with COVID-19, or to aid in the diagnosis of cases with unknown respiratory illness with fever [1]. Confirmation of the presence of the virus is done by detecting viral RNA in the patient's nasopharynx or other specimens using realtime Reverse Transcription Polymerase Chain Reaction (RT-PCR). Other tests such as serological antibody tests, rapid antigen detection, and other laboratory methods can support the diagnosis [2].

\section{BASIC STRUCTURES OF SEVERE ACUTE RESPIRATORY SYNDROME CORONAVIRUS 2}

Coronaviruses acquired their name because of the crown-like spikes on their surface. They are a family of positive-sense, spherical,

"Corresponding author. Email: mbelrem@hotmail.com

Peer review under responsibility of the Dr. Sulaiman Al Habib Medical Group nonsegmented, single-stranded, large (100-160 nm) RNA viruses with a genome of $26-32 \mathrm{~kb}$. This group has four major subgroups (genera) of coronaviruses known as alpha, beta, gamma, and delta. The first two genera mainly infect mammals while the latter two mainly infect birds. They can cause respiratory and gastrointestinal infections [3]. The recent coronavirus outbreaks were with Severe Acute Respiratory Syndrome Coronavirus (SARS-CoV), Middle East respiratory syndrome coronavirus, and recently the SARSCoV-2 pandemic; all of which belong to the beta coronaviruses [4]. This group of viruses can easily adapt to any environment by mutation and recombination to survive, leading to persistent and long-term health risks. Therefore, it is necessary to recognize their virological properties to prevent their rapid spread and safety risks to humanity [5].

Severe Acute Respiratory Syndrome Coronavirus 2 is a large, 50-200 nm diameter, single-stranded RNA virus with a characteristic spherical or pleomorphic, nonsegmented envelope with characteristic crown-shape spikes or peplomers. The RNA is positive sense. It has four major structural proteins: including the spike protein (S), a glycoprotein that facilitates binding of envelope viruses to host cell angiotensin-converting enzyme 2 receptors with its S1 and S2; the small envelope glycoprotein (E), with its three variants, which is involved in viral assembly, virion release and pathogenesis; membrane glycoprotein $(M)$, which gives shape to the viral envelope and is responsible for transmembrane nutrient transport and bud release; nucleocapsid protein $(\mathrm{N})$, which is localized near the viral nucleic acid material within a capsid formed from the matrix protein and aids in packaging the viral RNA genome within the viral envelope, which is a fundamental component of viral self-assembly and replication; and several other accessory 
proteins (Figure 1) [6,7]. The coronavirus genome encodes four or five major structural proteins: S, M, E, N, and hemagglutinin esterase. The genome of SARS-CoV-2 consists of 29,903 nucleotides, composed of four main genes encoding the major structural proteins $\mathrm{S}, \mathrm{E}, \mathrm{M}$, and $\mathrm{N}$, and another six accessory genes occupying about two-thirds of the viral genome and encoding Open Reading Frame (ORF)1a and b, ORF3a, ORF6, ORF7a, ORF7b, ORF8, and ORF10 proteins, and noncoding sequences (Figure 2) [8].

There are three well-defined variants of SARS-CoV-2 according to their genomic differences. They consist of groups with closely related lineages, referred to as $\mathrm{A}, \mathrm{B}$, and $\mathrm{C}$, which differ by amino acid variations, with $\mathrm{A}$ being the ancestral type. The $\mathrm{A}$ and $\mathrm{C}$ types are present in appreciable percentages out of East Asia (common in Americans and Europeans) as they resist the B type which is the most common variant in Far and East Asia $[9,10]$.

\section{MUTATIONS IN CORONAVIRUSES}

Although SARS-CoV-2 is a single-stranded RNA virus, which tends to mutate more frequently than any other virus type, unlike the other RNA viruses, it does so slowly, with an average mutation rate of one per month. Certain mutations could potentially create strains that are more deadly than others or are better at spreading the virus. For example, a gene coding a mutation of the spike

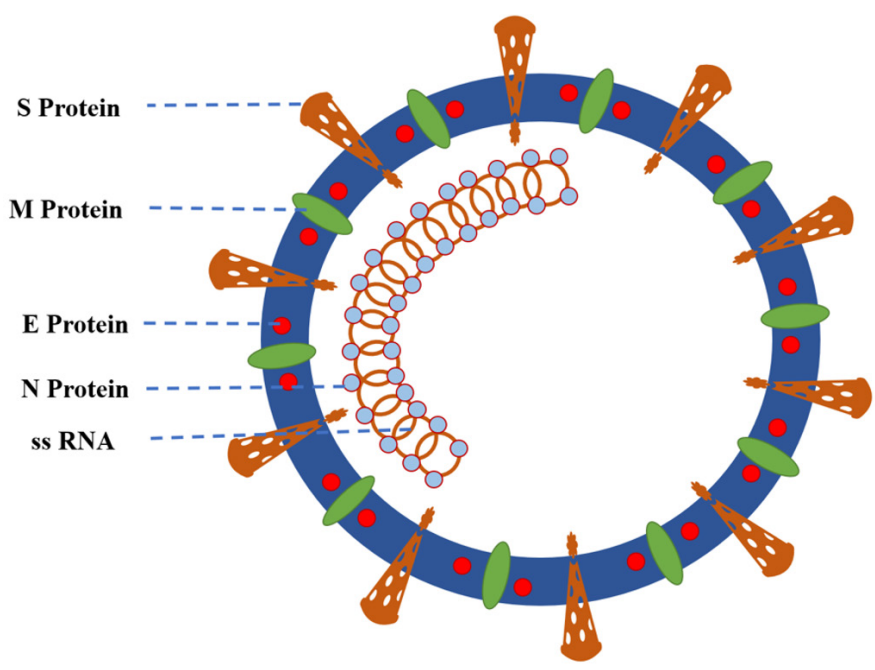

Figure 1 Structure of severe acute respiratory syndrome coronavirus 2. The coronaviral genome encodes four major structural proteins: S, N, M, and E; all of which are vital to create structurally complete viral particles. The E protein is the smallest of the four major structural proteins. E, envelope protein; $\mathrm{M}$, matrix or membrane protein; $\mathrm{N}$, nucleoprotein; S, spike protein; ssRNA, single-stranded RNA $(27-31.5 \mathrm{~kb})$. protein gives it reduced shedding ability, greater flexibility, and an advantage in transmissibility over other strains of the virus [11,12]. The virus mutates as it migrates through countries; it responds to evolutionary pressures from localized populations with different immune responses or using different antiviral drugs. This pressure leads to the emergence of different strains. Over time, this could lead to strains that are resistant to drugs, complicating the global efforts to defeat the pandemic. Due to the random nature of mutations, their effects and consequences cannot be predicted [13]. Therefore, it is important to track mutation evolution even if we have an effective vaccine against COVID-19. Continuous sequencing of the virus would still be essential to understand how changes in the virus might alter its lethality, transmissibility, and the efficacy of a vaccine against all strains. Rapid sharing of data is key to understanding whether the virus is changing and how it is transmitted.

\section{MOLECULAR TESTING FOR COVID-19}

Diagnostic approaches to COVID- 19 include clinical, radiological, and laboratory tools. Laboratory tests can be used for confirmation of infection, staging of disease severity, treatment monitoring, prognosis, and epidemiological surveillance (Figure 3). The two main categories of tests used include nucleic-acid-dependent and serology-dependent tests. Nucleic-acid-dependent tests immediately screen for viral RNA molecules from the patient's nasal or pharyngeal cavity, while serology-dependent tests identify the presence of the specific antibodies against SARS-CoV-2 in the patient's serum [14]. Nucleic acid tests have higher detection rates in the early days of infection when the viral load is expected to be high, so that a single swab from the patient's nasopharynx may contain nearly 1 million SARS-CoV-2 particles [15]. By contrast, the serological tests, which depend on the patient's response by detecting IgG and IgM antibodies, typically become positive within 5-10 days after the onset of symptoms [16].

Nucleic acid testing is the most sensitive and earliest detection method for the presence of RNA of SARS-CoV-2. Viral nucleic acid can be obtained from various types of specimens, including the upper respiratory tract (nasopharyngeal or oropharyngeal swab, aspiration of nasal secretions or nasal lavage, saliva, or midturbinate swab) or lower respiratory tract [Bronchoalveolar Lavage (BAL), tracheal aspirate, or sputum]. The highest detection accuracy for SARS-CoV-2 was observed in BAL (93\%), followed by sputum (72\%), then nasal swabs (63\%), and throat swabs (32\%). Combined throat/nasal swabs showed a similar result to nasopharyngeal swabs alone in detecting SARS-CoV-2. There is some evidence that stool, cerebrospinal fluid, plasma, urine, anal swabs, and other specimens can be used to detect SARS-CoV-2, but their diagnostic value is unclear [17-20]. Samples should be collected, shipped and stored under appropriate conditions. Inadequate

\begin{tabular}{|c|c|c|c|c|c|c|c|c|c|c|c|c|}
\hline $\begin{array}{l}5 \\
\text { UTR }\end{array}$ & $\begin{array}{c}\text { ORF1ab } \\
\text { Genes }\end{array}$ & $\underset{\text { Gene }}{\mathbf{S}}$ & $3 a$ & $\begin{array}{c}\mathrm{E} \\
\text { Gene }\end{array}$ & $\underset{\text { Gene }}{\text { M }}$ & $6 a$ & $7 a$ & $7 b$ & 8 & $\underset{\text { Gene }}{\mathbf{N}}$ & 10 & $\begin{array}{c}3 \\
\text { UTR }\end{array}$ \\
\hline $265 \mathrm{nt}$ & $21290 \mathrm{nt}$ & $3822 \mathrm{nt}$ & $828 \mathrm{nt}$ & $\begin{array}{c}228 \\
\text { nt }\end{array}$ & $669 \mathrm{nt}$ & $\begin{array}{c}186 \\
n t\end{array}$ & $366 \mathrm{nt}$ & $\begin{array}{c}132 \\
n t\end{array}$ & $\begin{array}{c}193 \\
\text { nt }\end{array}$ & 908 nt & $\begin{array}{c}117 \\
\text { nt }\end{array}$ & $\begin{array}{c}229 \\
\text { nt }\end{array}$ \\
\hline
\end{tabular}

Figure 2 Schematic presentation of the genomic structure of severe acute respiratory syndrome coronavirus 2 with $5^{\prime}$ untranslated region (UTR) and 3' UTR and coding region of coronavirus disease 2019. 


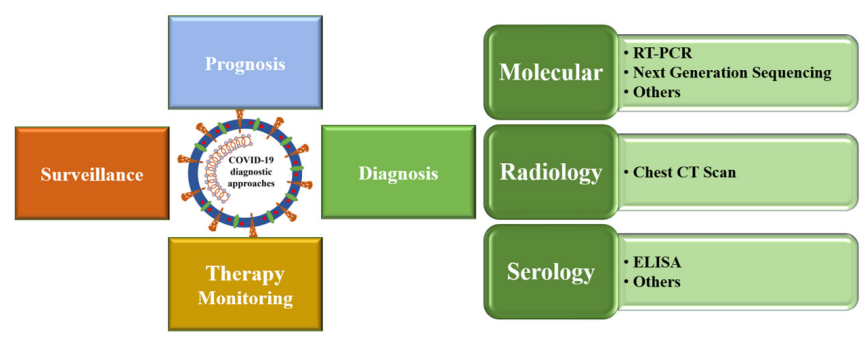

Figure 3 Schematic presentation of the diagnosis of coronavirus disease 2019.

sample collection, shipping, or storage of samples may compromise the ability of the test to identify the desired sequences [21]. The RT-PCR test is considered the gold standard for laboratory diagnosis of COVID-19. However, its performance requires specific reagents, tools, and training. RT-PCR provides qualitative and quantitative detection of nucleic acid for SARS-CoV-2 from either single or pooled samples [22].

The general flowchart for real-time RT-PCR testing includes the following main steps: sample collection and transport, extraction (lysis and purification of RNA), amplification, and detection. After sample collection and transport to the laboratory, lysis and inactivation of viral particles with chemical lysis buffers or by heating is performed, followed by extraction, purification, reverse transcription, amplification, and target identification. Amplification is performed by repeated cycles of denaturation, annealing, and extension by DNA polymerase enzymes with the primers, for example, ORF1ab, E, S, or $N$ genes targeting specific coding regions of SARS-CoV-2 RNA. With each cycle, the number of RNA particles copied is doubled. A positive control for the different procedures should be performed using specific primers for a human gene, for example, RNaseP. Identification of the amplified products is performed using various techniques such as TaqMan fluorescent probe or DNA-intercalating dyes. A threshold value is set for the amplification cycle (cycle threshold; $\mathrm{Ct}$ ) at which the test is considered positive and below which fluorescence is no longer detected and the test is considered negative. A test is usually considered positive if amplification can detect one or more of the viral target genes, while it is considered negative if amplification could not detect any viral targets while control RNA can be detected. Quantification of RT-PCR products can be broadly divided into two categories: endpoint (qualitative) and real-time (Quantitative; qRT-PCR). Both real-time qRT-PCR and qualitative RT-PCR (endpoint) are essentially the same PCR process. The difference is that in qRT-PCR the signal (fluorescent) at the end of each amplification cycle is captured to generate the amplification curve, whereas, in endpoint PCR, the assay is limited to the signal at the end of the process. There are promising alternatives to RT-PCR that have comparable sensitivity and specificity in detecting SARS-CoV-2, such as clustered regularly interspaced short palindromic repeatsbased detection, or isothermal amplification [14,23].

\section{LABORATORY CRITERIA FOR MOLECULAR DIAGNOSIS OF SARS-COV-2}

Authorization to perform molecular tests should be limited to laboratories with molecular diagnostic capabilities that meet the criteria for performing highly complex tests under the approval of the appropriate local health authority [24]. The professional staff must be well trained in the various sampling procedures from collection to real-time PCR testing techniques. The biosafety level of the laboratory should be level 2 in areas performing nonpropagative procedures (e.g., sequencing, nucleic acid amplification tests) and level 3 in areas performing propagative procedures (e.g., virus culture, isolation, or neutralization assays). The laboratory should be able to treat the patient specimens of suspected or confirmed cases during shipment as a biohazard, Category B, while being able to treat virus cultures or isolates as a biohazard, Category A, which is an infectious substance capable of causing harm to humans. The laboratory should be disinfected with appropriate disinfectants that have been shown to be effective against enveloped viruses. Phenolic compounds, quaternary ammonium compounds, hypochlorite (bleach), hydrogen peroxide, or alcohol are effective disinfectants. All laboratory personnel should strictly adhere to infection control measures and guidelines. Laboratories should be able to report positive results promptly to the appropriate national health authorities and platforms.

\section{POSITIVE OR NEGATIVE?}

No test has 100\% accuracy; therefore, each test should be evaluated for sensitivity and specificity, preferably by comparison to a gold standard. The lack of such a well-defined gold standard for COVID-19 testing makes evaluating test accuracy a major challenge. The sensitivity of the molecular test in detecting SARSCoV-2 depends on the method and type of sample collected, as well as on the population tested. It also depends on the sensitivity of the reagent kits, equipment used, and the experience of the personnel performing the test. Many factors should be considered when selecting a particular assay, such as the cost, turnaround time, instrument throughput, availability of reagents, sensitivity, and specificity of the desired test. Consideration should also be given to the underlying population being tested (e.g., contact tracing versus diagnosis of clinical cases), the potential clinical impact, and the important public health implications if COVID-19 cases are missed [19]. When a low viral load is expected, such as in healthcare professionals with no or mild symptoms, or in patients recovering from an infection, it is recommended to use diagnostic tools with high sensitivity and diagnostic yield that can best identify positive clinical specimens [25]. SARS-CoV-2 RNA can generally be detected in respiratory specimens during the early acute stage of infection. Positive results indicate the presence of SARS-CoV-2 RNA but do not necessarily mean that it is the cause of the disease. Clinical correlation with patient history and other diagnostic tools is essential to determine the infectivity of the patient. Positive results do not rule out bacterial or other viral coinfections. The pathogen detected may not be the exact cause of the illness. While positive tests are clinically valuable, negative tests should be viewed with greater caution, considering the possibility of having the disease before the test. Negative results do not rule out infection with SARS-CoV-2 and should not be used as the sole decision indicator for patient management. A single negative test result may not be meaningful if the pretest probability is high. Negative results should be supplemented with clinical status, patient history, radiological examination, and epidemiological data [26]. 
False-positive or -negative test results have a great impact on pandemic management. False-positive results lead to unnecessary treatment as well as community-related problems, as they can destabilize the workforce available to manage this pandemic when they affect those working in public services. However, a falsenegative test can potentially contribute to the further spread and dissemination of SARS-CoV-2 within the community [26]. Falsenegative results are more common than false-positive results and are related to many factors, such as poor collection technique, decay of viral RNA particles during transport/storage, use of poor and deficient extraction methods, presence of RT-PCR inhibitors, new genetic mutations in SARS-CoV-2, or failure to follow correct instructions for use. Conversely, a false-positive result may result from contamination of specimens during handling or preparation. It can also result from mixing of samples or contamination of RNA materials during product processing [27]. The double target test will improve both diagnostic accuracy and sensitivity, thus improving the proper clinical response to this pandemic [28]. The lack of a well-defined gold standard is a major challenge in evaluating COVID-19 testing; rationally, clinical judgment may be the best available gold standard, depending on repeated swabs, history of exposure to individuals known to have COVID-19, chest radiographs, and computed tomography scans [29].

\section{Ct VALUES: FACT OR FICTION?}

In real-time qRT-PCR, a positive reaction is noted by the accumulation of the fluorescent signals with each amplification cycle. $\mathrm{Ct}$ is defined as the number of amplification cycles required to accumulate enough fluorescent signals to exceed the threshold (Figure 4). $\mathrm{Ct}$ values are inversely related to the amount of target nucleic acids in the sample before amplification started (i.e., the lower the $\mathrm{Ct}$ value, the greater the amount of target nucleic acid in the sample). Low $\mathrm{Ct}$ values indicate strong positive reactions, indicating the presence of a large amount of target nucleic acids in the sample,

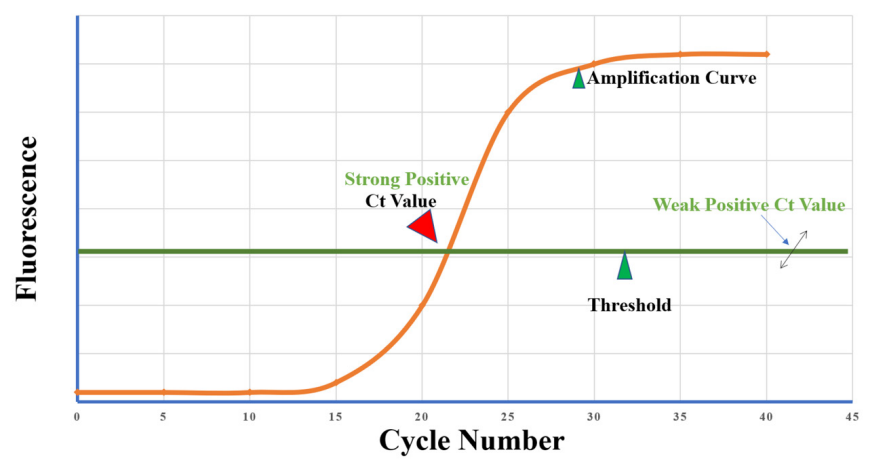

Figure 4 Cycle threshold (Ct) of reverse transcription polymerase chain reaction of severe acute respiratory syndrome coronavirus 2 . Fluorescence is the intensity of fluorescence light. The threshold line is set to determine the lowest level of fluorescence light detection or the point at which the amplification reaction was able to reach a fluorescent intensity above background levels (which is set by the manufacturers). Ct value is the minimum number of cycles that can amplify the target to absorb fluorescence light. Ct value is the joint point between the amplification cycle curve and the threshold line; if the cycle number is below the threshold line, there is no Ct value. which may indicate a high viral load. A high Ct value indicates a weak response, suggesting the presence of negligible amounts of target nucleic acid in the sample, which could represent either an infectious state or environmental contamination [30]. The Ct value is the relative indicator of the amount of the target in the PCR. It gives an indirect indication of viral load (relative rather than absolute). There is a considerable debate on the acceptable Ct value as it differs according to the type of kits, manufacturer, and equipment used. Each diagnostic kit has its threshold value to define a positive or negative presence of the target molecule [22]. Many factors can negatively affect the $\mathrm{Ct}$ value, such as the threshold of the instrument to detect fluorescence or the concentration of nucleic acids, which is affected by many conditions, including the technique of swab collection and transport, extraction procedure, pipetting technique, reagents, and kits with different primers and probes, and the presence of degraded polymerase enzyme. A qualitative positive or negative PCR is usually adequate for routine diagnosis but is not appropriate to measure the viral load. A systematic assessment of the adequacy and strength of the standard curve is essential to accurately calculate the expected viral copy number. There is still great heterogeneity and discrepancies of standard curves derived from the studies reporting $\mathrm{Ct}$ values from sequential dilution of samples and expected viral loads [31].

There are conflicting data on the clinical implications of the $\mathrm{Ct}$ value. Some studies have found that patients with severe symptoms may have a high viral load, up to 60 times that of patients with mild symptoms [32]. Some researchers rely on the Ct value as a testbased decision to stop patient isolation, considering that infectivity is low in patients with Ct values $>24$. Moreover, they consider that positive RT-PCR results in a patient without symptoms and a $\mathrm{Ct}$ value of 38 on day 29 after the first positive RT-PCR are due to the presence of residual viral genomic RNA, without live virus [33]. Conversely, even if $\mathrm{Ct}$ value is thought to indirectly represent viral load, researchers have shown that symptomatic and asymptomatic individuals may have similar amounts of viral load [34]. There are not yet enough studies correlating the Ct values with disease severity or contagiousness. High Ct values give a false sense of security, although there is not enough evidence that a higher $\mathrm{Ct}$ value indicates low infectivity. Ct values are typically not a quantifiable estimate of viral load and are not consistent across RT-PCR platforms; therefore, the use of $\mathrm{Ct}$ values to assess the status of an individual who is expected to be no longer infectious is not approved or recommended by the US Centers for Disease Control [35]. Thus, we should rely on the clinical situation as an adjuvant to molecular testing.

\section{VIRAL SHEDDING: PERSISTENT INFECTION OR REINFECTION?}

Some patients may become positive after being negative by RT-PCR testing for two consecutive samples. This could be due to either persistent infection or reinfection. Persistent viral RNA material can usually be expected to have higher Ct values (i.e., lower RNA copy number) than $\mathrm{Ct}$ values from specimens obtained shortly before or during clinical illness. Persistent viral shedding may continue in feces after it has disappeared from respiratory secretions. Viral shedding from the respiratory tract peaks on the seventh day after infection, just before, and with the onset of symptoms [36]. Fecal viral shedding may persist for 6-10 days after the throat swabs 
are negative, regardless of COVID-19 severity. Fecal viral shedding may persist even after improvement of gastrointestinal symptoms including diarrhea and may persist for up to 47 days after the onset of symptoms in some patients with COVID-19 [37]. Viral shedding may be irregular, erratic and not constant. A single negative smear result may be deceptive, and the test may need to be repeated. Some studies have shown that this shedding can last for several weeks. A study done by Zhou et al. [38] showed that the average duration of viral shedding was about 31 days from disease onset, and the average total duration from disease onset to discharge was about 40 days.

Li et al. [39] reported a patient in whom viral shedding continued for about 2 months from symptoms onset and for 5 weeks after she was completely asymptomatic. Male patients with COVID-19 are more prone to persistent viral shedding. Other factors that may play a role in persistent viral shedding include delayed diagnosis and hospital admission after symptom onset, use of immunosuppression, severity of illness, especially if mechanical ventilation is required, delayed antiviral therapy, and presence of other comorbidities such as coronary artery disease [40]. Inflammatory markers suggestive of persistent viral shedding include low serum albumin levels, high soluble interleukin-2 receptor, and high lactate dehydrogenase levels [41]. The clinical significance of persistent viral shedding after recovery and potential infectivity are not yet known as there is no obvious relationship between viral load and patient infectivity. To date, there is limited evidence that individuals with clinical recovery and persistent or recurrent shedding of viral RNA can transmit SARS-CoV-2 to others. However, it is not assured that all individuals with persistent or recurrent SARS-CoV-2 RNA shedding are no longer infectious [42].

Although rare, a recurrence of COVID-19 has been described, which could be either a reinfection or a reactivation of the disease [43-45]. Immunity developed in response to infection with SARSCoV-2 depends on both cell-mediated and humoral immunity. However, their precise role in clearing viral infection and protecting against reactivation or recurrence is uncertain. Induced antibodies to SARS-CoV-2 infection decrease after 2-3 months, which is a normal phenomenon that occurs after the acute infection has resolved. Recurrence may occur due to a suboptimal eradication of SARS-CoV-2 infection, which allows viral replication to flare up again. Immunodeficiency due to medication or secondary to congenital or acquired disease may play a role in impaired viral wash out and promote reactivation of SARS-CoV-2. Recurrence of COVID-19 must be distinguished from the occurrence of secondary known complications of COVID-19 such as bacterial or viral superinfection, or pulmonary embolism. It should also be distinguished from persistence of viral shedding [46]. Viral culture and genomic studies capable of comparing the viral strains causing both episodes can help to distinguish between three conditions: persistent viral shedding, reinfection, or recurrence [46].

Because of the important role they play, assessment of both innate and acquired immunity and monitoring inflammatory markers would be of value in understanding the underlying pathophysiological mechanism of COVID-19 recurrence [46]. Viral or bacterial coinfection should also be ruled out. Similarly, an inflammatory rebound phenomenon caused by an inappropriate immune response can potentially cause the same symptoms and signs leading to confusion with recurrence. Detection of viral RNA in all patients with a possible relapse - some of whom have a low $\mathrm{Ct}$ and verification of the viral strain involved in the second episode either by genomic studies or by viral cultures could help distinguish between a new episode of infection (reinfection) and either viral reactivation or an immune response-dependent inflammatory rebound phenomenon $[47,48]$. Laboratory tests help to distinguish between viral shedding, reinfection, or inflammatory rebound. We should be careful in interpreting laboratory tests, considering the type and timing of specimen collection, and identifying intermittent and erratic viral shedding. We should also consider the clinical status of the patients and the differences in sensitivities and specificities of the various test methods.

\section{CONCLUSION}

There are many points of debate in the laboratory diagnosis of COVID-19. Since molecular diagnostic tests are the cornerstone of diagnosis, continuous updating is imperative. The clinician should not rely solely on the laboratory diagnosis, and the clinical condition of the patients should be considered.

\section{CONFLICTS OF INTEREST}

The authors declare they have no conflicts of interest.

\section{AUTHORS' CONTRIBUTION}

NKS, MAB and ASB equally shared in writing and reviewing the manuscript.

\section{FUNDING}

No financial support was provided.

\section{ACKNOWLEDGMENTS}

We acknowledge the reviewers and editors who spent time to review this article.

\section{REFERENCES}

[1] Hong KH, Lee SW, Kim TS, Huh HJ, Lee J, Kim SY, et al. Guidelines for laboratory diagnosis of coronavirus disease 2019 (COVID-19) in Korea. Ann Lab Med 2020;40;351-60.

[2] Lim J, Lee J. Current laboratory diagnosis of coronavirus disease 2019. Korean J Intern Med 2020;35;741-8

[3] Wu A, Peng Y, Huang B, Ding X, Wang X, Niu P, et al. Genome composition and divergence of the novel coronavirus (2019$\mathrm{nCoV}$ ) originating in China. Cell Host Microbe 2020;27;325-8.

[4] Rabaan AA, Al-Ahmed SH, Haque S, Sah R, Tiwari R, Malik YS, et al. SARS-CoV-2, SARS-CoV, and MERS-COV: a comparative overview. Infez Med 2020;28;174-84.

[5] Paules CI, Marston HD, Fauci AS. Coronavirus infections-more than just the common cold. JAMA 2020;323;707-8. 
[6] Kumar R, Nagpal S, Kaushik S, Mendiratta S. COVID-19 diagnostic approaches: different roads to the same destination. Virus Dis 2020;31;97-105.

[7] Astuti I, Ysrafil. Severe acute respiratory syndrome coronavirus 2 (SARS-CoV-2): an overview of viral structure and host response. Diabetes Metab Syndr 2020;14;407-12.

[8] Khailany RA, Safdar M, Ozaslan M. Genomic characterization of a novel SARS-CoV-2. Gene Rep 2020;19;100682.

[9] Forster P, Forster L, Renfrew C, Forster M. Phylogenetic network analysis of SARS-CoV-2 genomes. Proc Natl Acad Sci U S A 2020;117;9241-3.

[10] Biswas NK, Majumder PP. Analysis of RNA sequences of 3636 SARS-CoV-2 collected from 55 countries reveals selective sweep of one virus type. Indian J Med Res 2020;151;450-8.

[11] Qiang XL, Xu P, Fang G, Liu WB, Kou Z. Using the spike protein feature to predict infection risk and monitor the evolutionary dynamic of coronavirus. Infect Dis Poverty 2020;9;33.

[12] Zhang L, Jackson CB, Mou H, Ojha A, Rangarajan ES, Izard T, et al. The D614G mutation in the SARS-CoV-2 spike protein reduces S1 shedding and increases infectivity. bioRxiv 2020;2020. 06.12.148726.

[13] Dawood AA. Mutated COVID -19 may foretell a great risk for mankind in the future. New Microbes New Infect 2020;35;100673.

[14] Esbin MN, Whitney ON, Chong S, Maurer A, Darzacq X, Tjian R. Overcoming the bottleneck to widespread testing: a rapid review of nucleic acid testing approaches for COVID-19 detection. RNA 2020;26;771-83.

[15] Wölfel R, Corman VM, Guggemos W, Seilmaier M, Zange S, Müller MA, et al. Virological assessment of hospitalized patients with COVID-2019. Nature 2020;581;465-9.

[16] Yang Y, Yang M, Shen C, Wang F, Yuan J, Li J, et al. Evaluating the accuracy of different respiratory specimens in the laboratory diagnosis and monitoring the viral shedding of 2019-nCoV infections. medRxiv 2020 [Preprint].

[17] Zhang J, Wang S, Xue Y. Fecal specimen diagnosis 2019 novel coronavirus-infected pneumonia. J Med Virol 2020;92;680-2.

[18] Wang W, Xu Y, Gao R, Lu R, Han K, Wu G, et al. Detection of SARS-CoV-2 in different types of clinical specimens. JAMA 2020;323;1843-4.

[19] Bulterys PL, Garamani N, Stevens B, Sahoo MK, Huang C, Hogan $\mathrm{CA}$, et al. Comparison of a laboratory-developed test targeting the envelope gene with three nucleic acid amplification tests for detection of SARS-CoV-2. J Clin Virol 2020;129;104427.

[20] Vlek ALM, Wesselius TS, Achterberg R, Thijsen SFT. Combined throat/nasal swab sampling for SARS-CoV-2 is equivalent to nasopharyngeal sampling. Eur J Clin Microbiol Infect Dis 2021; 40;193-5.

[21] Udugama B, Kadhiresan P, Kozlowski HN, Malekjahani A, Osborne M, Li VYC, et al. Diagnosing COVID-19: the disease and tools for detection. ACS Nano 2020;14;3822-35.

[22] Corman VM, Landt O, Kaiser M, Molenkamp R, Meijer A, Chu DKW, et al. Detection of 2019 novel coronavirus (2019-nCoV) by real-time RT-PCR. Euro Surveill 2020;25;2000045.

[23] Biswas B. Clinical performance evaluation of molecular diagnostic tests. J Mol Diagn 2016;18;803-12.

[24] CDC. Lab advisory: FDA guidance to develop novel molecular diagnostic tests for SARS-CoV-2. 2020. Available from: https://www.cdc.gov/csels/dls/locs/2020/fda_guidance_to_ develop_novel_molecular_diagnostic_tests_for_sars-cov-2.html (accessed April 27, 2021).
[25] van Kasteren PB, van der Veer B, van den Brink S, Wijsman L, de Jonge J, van den Brandt A, et al. Comparison of seven commercial RT-PCR diagnostic kits for COVID-19. J Clin Virol $2020 ; 128 ; 104412$.

[26] Younes N, Al-Sadeq DW, Al-Jighefee H, Younes S, Al-Jamal O, Daas HI, et al. Challenges in laboratory diagnosis of the novel coronavirus SARS-CoV-2. Viruses 2020;12;582.

[27] Feng W, Newbigging AM, Le C, Pang B, Peng H, Cao Y, et al. Molecular diagnosis of COVID-19: challenges and research needs. Anal Chem 2020;92;10196-209.

[28] Colton H, Ankcorn M, Yavuz M, Tovey L, Cope A, Raza M, et al. Improved sensitivity using a dual target, E and RdRp assay for the diagnosis of SARS-CoV-2 infection: experience at a large NHS Foundation Trust in the UK. J Infect 2021;82;159-98.

[29] Watson J, Whiting PF, Brush JE. Interpreting a covid-19 test result. BMJ 2020;369;m1808.

[30] Schmittgen TD, Livak KJ. Analyzing real-time PCR data by the comparative $C_{\mathrm{T}}$ method. Nat Protoc 2008;3;1101-8.

[31] Han MS, Byun JH, Cho Y, Rim JH. RT-PCR for SARS-CoV-2: quantitative versus qualitative. Lancet Infect Dis 2021;21;165.

[32] Liu Y, Yan LM, Wan L, Xiang TX, Le A, Liu JM, et al. Viral dynamics in mild and severe cases of COVID-19. Lancet Infect Dis 2020;20;656-7.

[33] Bordon J, Chung D, Krishnan P, Carrico R, Ramirez JA. The importance of cycle threshold values in the evaluation of patients with persistent positive PCR for SARS-CoV-2: case study and brief review. Univ Louisville J Resp Infec 2020;4;54.

[34] Lee S, Kim T, Lee E, Lee C, Kim H, Rhee H, et al. Clinical course and molecular viral shedding among asymptomatic and symptomatic patients with SARS-CoV-2 infection in a community treatment center in the Republic of Korea. JAMA Intern Med 2020; $180 ; 1447-52$.

[35] Centers for Disease Control and Prevention. Duration of isolation and precautions for adults with COVID-19. 2020. Available from: https://www.cdc.gov/coronavirus/2019-ncov/hcp/durationisolation.html (accessed April 27, 2021).

[36] Beeching NJ, Fletcher TE, Beadsworth MBJ. Covid-19: testing times. BMJ 2020;369;m1403.

[37] Gupta S, Parker J, Smits S, Underwood J, Dolwani S. Persistent viral shedding of SARS-CoV-2 in faeces - a rapid review. Colorectal Dis 2020;22;611-20.

[38] Zhou B, She J, Wang Y, Ma X. Duration of viral shedding of discharged patients with severe COVID-19. Clin Infect Dis $2020 ; 71 ; 2240-2$.

[39] Li J, Zhang L, Liu B, Song D. Case report: viral shedding for 60 days in a woman with COVID-19. Am J Trop Med Hyg 2020;102;1210-13.

[40] Xu K, Chen Y, Yuan J, Yi P, Ding C, Wu W, et al. Factors associated with prolonged viral RNA shedding in patients with coronavirus disease 2019 (COVID-19). Clin Infect Dis 2020;71;799-806.

[41] Fu Y, Han P, Zhu R, Bai T, Yi J, Zhao X, et al. Risk factors for viral RNA shedding in COVID-19 patients. Eur Respir J 2020; 56;2001190.

[42] Widders A, Broom A, Broom J. SARS-CoV-2: the viral shedding vs infectivity dilemma. Infect Dis Health 2020;25;210-15.

[43] Ye G, Pan Z, Pan Y, Deng Q, Chen L, Li J, et al. Clinical characteristics of severe acute respiratory syndrome coronavirus 2 reactivation. J Infect 2020;80;e14-e17.

[44] Ravioli S, Ochsner H, Lindner G. Reactivation of COVID-19 pneumonia: a report of two cases. J Infect 2020;81;e72-e3. 
[45] Loconsole D, Passerini F, Palmieri VO, Centrone F, Sallustio A, Pugliese S, et al. Recurrence of COVID-19 after recovery: a case report from Italy. Infection 2020;48;965-7.

[46] Gousseff M, Penot P, Gallay L, Batisse D, Benech N, Bouiller K, et al. Clinical recurrences of COVID-19 symptoms after recovery: viral relapse, reinfection or inflammatory rebound?. J Infect $2020 ; 81 ; 816-46$.
[47] Lafaie L, Célarier T, Goethals L, Pozzetto B, Grange S, Ojardias E, et al. Recurrence or relapse of COVID-19 in older patients: a description of three cases. J Am Geriatr Soc 2020;68;2179-83.

[48] Soy M, Keser G, Atagündüz P, Tabak F, Atagündüz I, Kayhan S. Cytokine storm in COVID-19: pathogenesis and overview of anti-inflammatory agents used in treatment. Clin Rheumatol 2020;39;2085-94. 